\title{
Measuring High Surface Temperature in Concentrated Solar Radiation Environments
}

\author{
Jesús Ballestrín, María-Isabel Roldán \\ CIEMAT-Plataforma Solar de Almería, Solar Concentrating Systems Unit, Almería, Spain \\ Email address: \\ jesus.ballestrin@psa.es (J. Ballestrín) \\ To cite this article: \\ Jesús Ballestrín, María-Isabel Roldán. Measuring High Surface Temperature in Concentrated Solar Radiation Environments. American \\ Journal of Engineering and Technology Management. Vol. 2, No. 3, 2017, pp. 25-35. doi: 10.11648/j.ajetm.20170203.12
}

Received: March 7, 2017; Accepted: March 22, 2017; Published: October 15, 2017

\begin{abstract}
Surface temperature is a highly desired but difficult measurement especially in concentrated solar context. In this work a method for surface temperature measurement based on contact sensors is presented. In the case of materials with high thermal conductivity, contact sensors positioned in the back of the material sample and very close to the surface is the most accurate way to measure surface temperature. Computational Fluid Dynamics simulations have shown the truth of this statement. The higher thermal conductivity of the material, the lower the uncertainty in the measurement of surface temperature using this methodology. This measurement procedure has been applied to AISI $310 \mathrm{~S}$ steel samples in the Plataforma Solar de Almería vertical axis solar furnace SF5 confirming the validity of the simulations.
\end{abstract}

Keywords: Contact Sensor, High Temperature, Heat Transfer, Computational Fluid Dynamics (CFD), 2D Thermal Simulation

\section{Introduction}

The measurement of the temperature of a surface, when this temperature differs considerably from that of the environment, offers difficulties not encountered in the usual kind of temperature measurements, and many special devices and refinements of technique have been applied in problems of this kind. Knowledge of surface temperature is essential in many industrial and scientific applications, in particular, in many treatments of concentrated solar radiation [1-7]. To mention a few, information of surface temperature allows evaluating the thermal and convection losses of a system $[8,9]$ and determining the emittance of a material sample [10-14].

Non-contact or infrared or pyrometric sensors, though relatively expensive, are appropriate when the temperatures are extremely high. They are available for up to $3000 \mathrm{~K}$ far exceeding the range of contact devices. The infrared approach is also attractive when one does not wish to make contact with the surface whose temperature is to be measured. Thus, fragile or wet surfaces, such as painted surfaces coming out of a drying oven, can be monitored in this way. Substances that are chemically reactive or electrically noisy are ideal candidates for infrared measurement. The approach is likewise advantageous in measuring temperature of very large surfaces, such as walls that would require a large array of contact sensors. A difficulty with pyrometric temperature measurement is, however, that the detector responds to solar radiation which is directly reflected from the irradiated sample, as well as re-radiation. This problem has been partially resolved with the design and manufacturing of solar-blind pyrometers and cameras [1524]. On the other hand, the determination of the real temperature requires knowledge of the surface emittance, as the temperature is determined on the basis of the current signal generated by the radiant surface compared to the signal generated by a blackbody calibrator. In most cases the value of the emittance of the surface to be measured is unknown. In these cases the uncertainty in the temperature measurement is unknown and must be used a more reliable measurement technique as contact sensors.

When a surface is subjected to concentrated solar radiation contact sensors must be positioned on its back to prevent the solar influence on the measurement. Contact temperature sensors measure their own temperature. One infers the 
temperature of the object to which the sensor is in contact by assuming or knowing that the two are in thermal equilibrium, that is, there is no heat flow between them. An attempt must be made to make the surface and sensor temperatures the same. This can be done by placing insulation over the sensor to reduce the effects of the environment and by choosing a mounting method that provides good thermal contact between surface and sensor.

This paper presents Computational Fluid Dynamics (CFD) simulations showing that, in the case of materials with good thermal conductivity, contact sensors positioned in the back of the material sample and very close to the surface is the most accurate way to measure surface temperature. The higher thermal conductivity of the material, the lower the uncertainty in the measurement of surface temperature using this methodology. This measurement procedure has been applied to AISI 310 S steel samples in the Plataforma Solar de Almería (PSA) vertical axis solar furnace SF5 confirming the validity of the simulations.

\section{Non-contact Measurement Techniques}

Surface temperature measurement problem can be solved in many cases through the use of non-contact sensors; they are almost ideal for those types of applications and are in use in many industrial plants worldwide in great numbers. However, in many cases, ignorance of the emittance of the surface generates a great uncertainty in the measurement of surface temperature. Being optimistic and assuming a $\pm 10 \%$ uncertainty in the emittance, the uncertainty in the measurement of temperature would be approximately $\pm 3 \%$ from the Stefan-Boltzman law. Assuming a surface temperature of $1273 \mathrm{~K}$, the uncertainty caused by emittance would be $\pm 38 \mathrm{~K}$. Uncertainty in the measurement of the surface temperature can be much higher in an environment of concentrated solar radiation, unknown in most cases, due to the influence of the reflected solar radiation. Below it will be shown that this margin of uncertainty can be reduced largely by contact sensors in materials with high thermal conductivity.

\section{Contact Measurement Techniques}

There are a number of standard approaches to contact measurement of temperature which find application in CST receivers, particularly for distributed measurement at a number of points. The three most common types of contact sensors are thermocouples, Resistance Temperature Detectors (RTD), and thermistors. Thermistors are manufactured with a maximum usable temperature between 423 and $573 \mathrm{~K}$. RTD sensors are generally more stable and accurate than thermocouples, but are less robust and have a temperature range up to the order of $923 \mathrm{~K}$, compared to over $1273 \mathrm{~K}$ for K-type thermocouples. Detailed descriptions of these and other temperature measurement technologies, with discussion of the methods used to obtain the highest possible accuracy, are given in Agilent
Technologies [25] and Baker et al. [26].

Thermocouples consist of a pair of wires made from dissimilar metals which are joined at one end. If there is a temperature difference between the junction (which is used as the temperature probe) and the other ends of the wires a small voltage is produced, which is dependent on the particular metals being used, and on the temperature difference. Standard calibration curves give the temperature differential as a function of output voltage for a wide range of thermocouple material types; these curves are commonly built into data acquisition hardware. In order to obtain an absolute measurement the temperature at the ends of the wires (known as the "cold junction") must be determined independently and added to the temperature differential. Data acquisition equipment usually has an internal temperature sensor for this purpose.

Thermocouples are classified according to the pair of metals employed and the temperature calibration range; "Ktype" thermocouples typically have $\pm 2 \mathrm{~K}$ accuracy, up to a standard maximum temperature of $1523 \mathrm{~K}$. The insulation material on the thermocouple wires may however impose a lower maximum temperature. For example, PTFE insulated sensors are rated to approximately $523 \mathrm{~K}$, fibreglass insulation $623 \mathrm{~K}$ or higher and mineral insulation over 1273 $\mathrm{K}$. Other factors to take into account when choosing thermocouples are mechanical robustness and flexibility. Thermocouples can be enclosed in a stainless steel or Inconel sheath as a barrier or seal between the working fluid, or for protection against mechanical damage.

\section{PSA Vertical Axis Solar Furnace SF5}

The highest energy levels possible with a solar concentrating system are reached in solar furnaces, where concentrations of over $10000 \mathrm{X}$ have been attained. A solar furnace essentially consists of a flat solar-tracking heliostat, a parabolic collector mirror, an attenuator or shutter and the test zone located in the concentrator focus (Figure 1). The flat collector mirror, or heliostat, reflects the solar beams on the parabolic dish, which in turn reflects them on the test area in its focus. The amount of incident light is regulated by the shutter located between the concentrator and the heliostat. A test table movable in three directions (East-West, NorthSouth, up and down) places the test samples in the focus with great precision. The main advantage of vertical axis solar furnaces is that the samples are deposited, without the need of any fixation, on a horizontal plane where they can be treated directly in the focus.

This PSA vertical axis solar furnace SF5 is able to deliver up to $5 \mathrm{~kW}$ power at peak concentration ratios exceeding 7000 and focus size $25 \mathrm{~mm}$ diameter approximately. This solar furnace [27] has one $25 \mathrm{~m}^{2}$ heliostat. The reflective surface of the heliostat, which is made up of 25 nonconcentrating flat facets of $1 \mathrm{~m}^{2}$ with reflectivity higher than $0.95 \%$, continuously tracks the solar disk and reflects its parallel vertical beams onto the concentrator. 
<smiles>Cc1c(C)c(C)c(C)c(C)c1C</smiles>

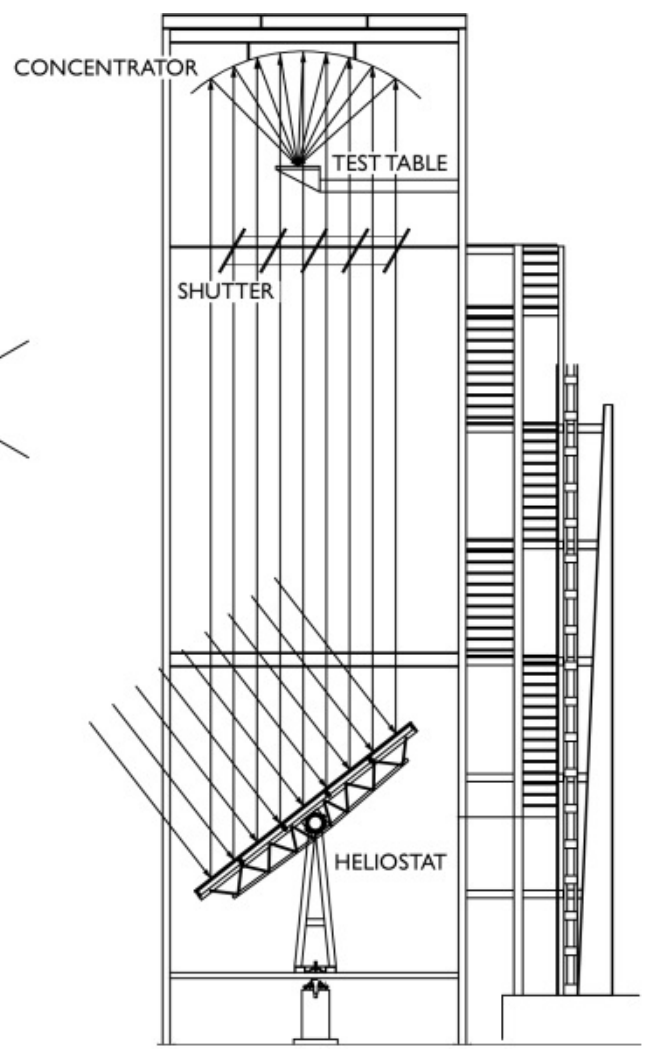

Figure 1. Solar Furnace SF5 diagram.

The concentrator dish, which concentrates the incident light from the heliostat, multiplying the radiant energy in the focal zone, is the main component of the solar furnace (Figure 1). Its optical properties especially affect the irradiance distribution at the focus. It consists of 54 hexagonal, $25 \mathrm{~cm}$ radius facets of $1623.78 \mathrm{~cm}^{2}$ surface. Its contour is quasi circular with $3.5 \mathrm{~m}$ diameter and a total area of $8.77 \mathrm{~m}^{2}$. For economic reasons, the facets are all identical, spherical curvature with a focal distance of $2 \mathrm{~m}$ and radius of curvature $4 \mathrm{~m}$, double the focal distance.

The total energy in the focus is proportional to the radiation that passes through the louvered shutter, which is made up of 11 slats of $4 \mathrm{~m}$ long and $0.5 \mathrm{~m}$ wide under the test table, at $14 \mathrm{~m}$ above ground level. The slats are driven by a gear motor assembly which transmits its rotary movement to them through the straps, with a regulation accuracy of $0.1^{\circ}$. In the closed position the blades form an angle of $47.5^{\circ}$ with the vertical, while fully open the angle is $0^{\circ}$. The attenuator can be operated manually from the control panel and in automatic mode from the control computer Data Acquisition System (DAS).

\section{Experimental Setup}

The experimental setup consists of a steel plate (AISI 310) of $0.04 \times 0.04 \times 0.003 \mathrm{~m}$ (length $\mathrm{x}$ width $\mathrm{x}$ height) which is embedded in an alumina piece of $0.02 \times 0.02 \times 0.01 \mathrm{~m}$. The steel sample is heated by concentrating solar radiation that reaches the front surface of the steel plate (see Figure 2).

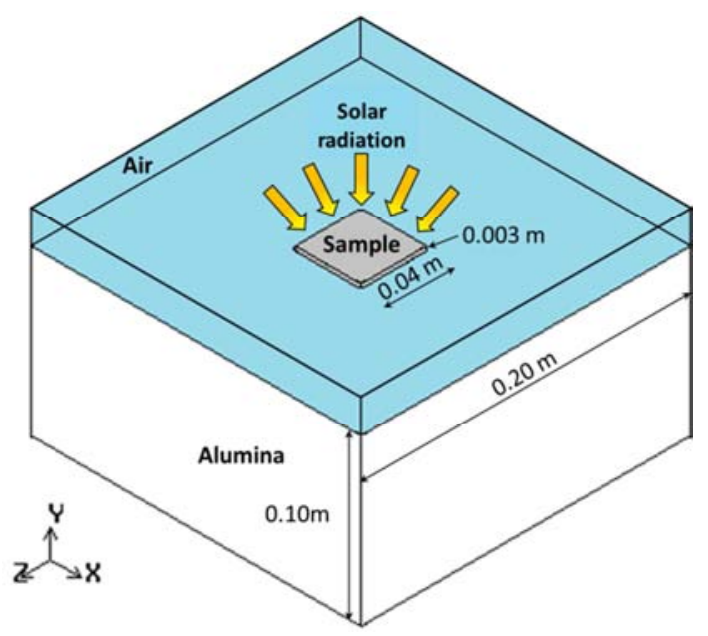

Figure 2. Setup scheme.

The thermal distribution of both steel sample and the insulating material (alumina) was obtained from the measurements of various K-type thermocouples Class I with a measurement uncertainty of $\pm 0.004 \cdot \mathrm{T}$ for the reached temperature range, according to IEC 60584.2 (1982). Six thermocouples were placed at the steel plate (Figure $3 \mathrm{a}$ ) at $0.8 \mathrm{~mm}$ from the surface and two were located inside the alumina block (Figure 3b). The thermocouples were distributed as shown in Figure 3.

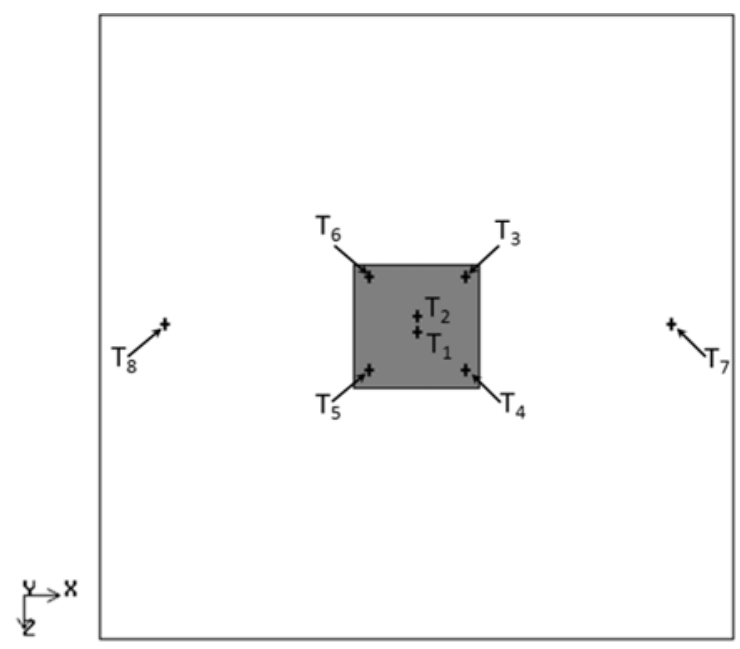

a)

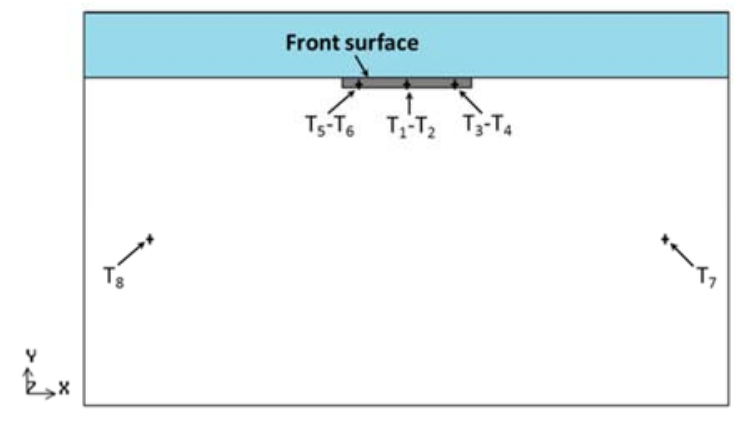

b)

Figure 3. Thermocouple locations: a) top distribution, b) front distribution. 


\section{Methodology}

\subsection{Procedure}

The purpose of this work is the evaluation of the uncertainty in high-temperature measurement on material surfaces by contact sensors. Thus, a CFD model has been developed in order to study the thermal distribution produced in a material sample when its upper surface is heated by concentrating solar radiation. This system reaches high temperatures which are difficult to measure with non-contact sensor because their measurements depend on optical properties such as emittance. As mentioned, these properties may change with the radiation wavelength and temperature, making it difficult to assess them with the required accuracy.

The developed CFD model consists of a two-dimensional (2D) geometry (see Figure $3 b$ ) which takes into account the alumina block, the sample and the air in contact with the radiated surface (Figure 2). Furthermore, three different quasi-steady states have been regarded when the back surface of the sample achieves temperatures of $873 \mathrm{~K}, 1073 \mathrm{~K}$ and $1273 \mathrm{~K}$. In order to define these cases, the temperature deviation obtained in the central area of the tested steel sample was evaluated considering the maximum and minimum temperature values reached within a 3-minute period. When this deviation is lower than $3 \%$, the instant selected is the one whose temperature is closest to the fixed one $(873 \mathrm{~K}, 1073 \mathrm{~K}$ or $1273 \mathrm{~K})$.

The CFD model was validated by the comparison of the temperature measured experimentally for an AISI 310 steel sample with the numerical values obtained at the same thermocouple locations and considering the same steel as sample material. The validated model has been used to study the applicability of contact sensors to measure the thermal distribution at mentioned conditions in samples of several thicknesses and materials. The analysed cases are summarised in

Table 1, in which it has been considered three sample thicknesses and three temperatures for a list of materials.

Table 1. Cases studied.

\begin{tabular}{lll}
\hline Material & $\begin{array}{l}\text { Sample } \\
\text { thickness (m) }\end{array}$ & $\begin{array}{l}\text { Temperature at the back } \\
\text { surface of the sample (K) }\end{array}$ \\
\hline $\begin{array}{l}\text { Copper (Cu) } \\
\text { Recrystallized Silicon }\end{array}$ & \\
Carbide (re-SiC) & \\
Steel (AISI 310) & & \\
Steel (AISI 304L) & 0.001 & 873 \\
Dense concrete 1 & 0.003 & 1073 \\
Dense concrete 2 & 0.01 & 1273 \\
Light weight concrete & & \\
Ceramic fibre & & \\
Alumina & \\
\hline
\end{tabular}

\subsection{Simulation Model}

\subsubsection{Numerical Modelling}

Fig. 2 shows a fluid (air) in contact with the elements considered in the experimental setup. The heat transfer between two solid materials which are in contact is only produced by conduction, whereas the dynamic behaviour of a fluid is defined by the three conservation laws (conservation of mass, momentum, and energy) [28]. This means that the continuity (1), momentum (2) [29] and energy (3) [30] equations described for the fluid medium must be solved by the CFD model:

$$
\begin{gathered}
\frac{\partial \rho}{\partial t}+\nabla \cdot(\rho \vec{v})=S_{m} \\
\frac{\partial}{\partial t}(\rho \vec{v})+\nabla \cdot(\rho \vec{v} \vec{v})=-\nabla p+\nabla \cdot(\bar{\tau})+\rho \vec{g}+\vec{F}
\end{gathered}
$$

$$
\frac{\partial}{\partial t}(\rho E)+\nabla \cdot(\vec{v}(\rho E+p))=\nabla \cdot\left(k_{e f f} \nabla T-\sum_{j} h_{j} \vec{J}_{j}+\left(\overline{\bar{\tau}}_{e f f} \cdot \vec{v}\right)\right)+S_{h e}
$$

where $\rho$ is the density of the fluid, $t$ is elapsed time, $\vec{v}$ is the velocity vector with respect to the coordinate system, $S_{m}$ is the mass source, $p$ is the static pressure, $\bar{\tau}$ is the stress tensor, $\rho \vec{g}$ is the gravitational body force, $\vec{F}$ is the external body force, $E$ is the energy transfer ( $\left.E=h-\frac{p}{\rho}+\frac{v^{2}}{2}\right), k_{\text {eff }}$ is the effective conductivity, $h_{j}$ is the enthalpy of species $j, \vec{J}_{j}$ is the diffusion flux of species $j, \bar{\tau}_{\text {eff }}$ is the viscous stress tensor, and $S_{h e}$ is the volumetric heat source. These general equations are regarded in two dimensions and, in this case, the air is the only species involved in the fluid medium. Furthermore, there is no forced circulation of the air and thus the selected viscous model was laminar.

\subsubsection{Geometry Definition and Mesh Design}

The solution domain is described in Figure $3 b$, in which the central cross section of the setup is shown. In this case, two dimensions have been considered in order to define a simple CFD model able to evaluate the accuracy of high-temperature measurements for different materials and thicknesses, while minimising the computational requirements in comparison with a complex and time-consuming model. This fact allows obtaining results in a shorter time.

Three subdomains have been defined in the solution domain (Figure 2): insulating material (alumina), material sample, and fluid (air).

The grid selected for this solution domain consisted of quadrilateral elements, corresponding to a $2 \mathrm{D}$ structured mesh (Figure 4). In order to evaluate the appropriateness of the mesh size, a grid independence test has been performed whose results have been collected in Table 2. Four different 
mesh sizes were evaluated and it was selected the one with the fewest elements together with the lowest deviation in the results. Thus, Mesh 2 was the grid selected for the calculation.

Table 2. Grid independence test.

\begin{tabular}{llll}
\hline Mesh & Mesh size & Temperature of the sample front surface, $\mathbf{K}$ & Temperature of the alumina front surface, K \\
\hline 1 & 11927 & 837.34 & 365.24 \\
2 & 27385 & 837.34 & 368.08 \\
3 & 31871 & 837.34 & 368.07 \\
4 & 36165 & 837.35 & 368.46 \\
\hline
\end{tabular}

For the purpose of evaluating the quality of Mesh 2, two parameters have been analysed: equiangle skew $\left(Q_{E A S}\right)$ and aspect ratio $\left(Q_{A R}\right)$.

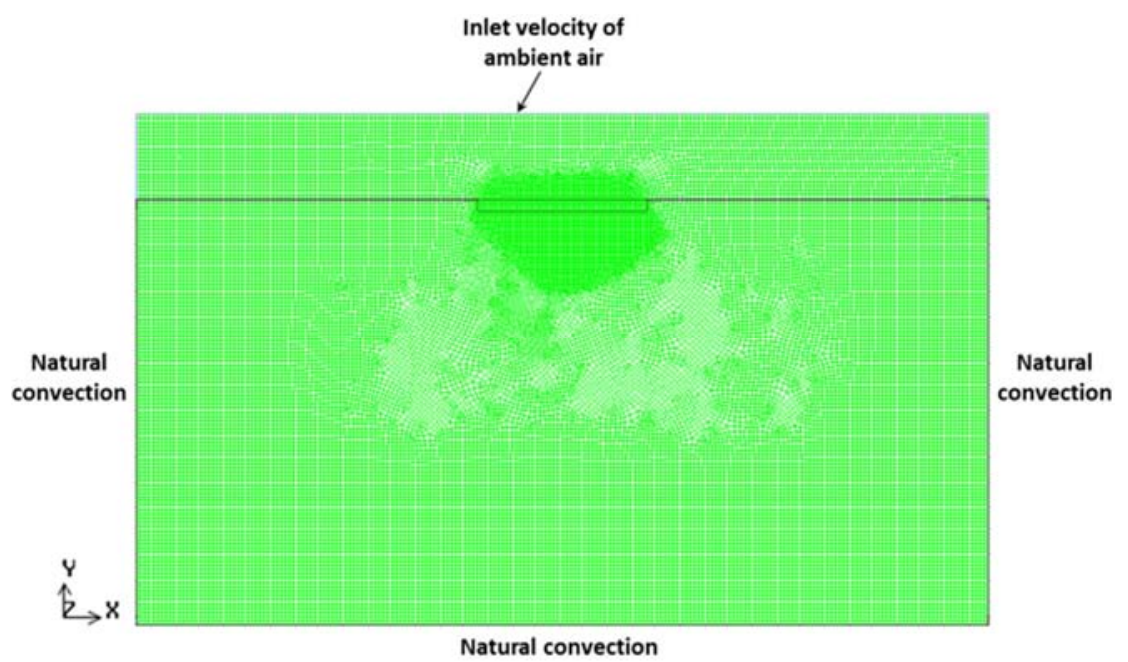

Figure 4. Mesh design and main boundary conditions.

The $Q_{E A S}$ is a normalised measure of skewness and, by definition, $0 \leq Q_{E A S} \leq 1$ [31]. The mesh element is equilateral when $Q_{E A S}$ is 0 and it has a poor shape when $Q_{E A S}$ is 1 . The analysis of the mesh quality is shown in Table 3, where $99.84 \%$ of the cells are included between the values of 0 and 0.5 . This range represents a good quality according to the relationship between $Q_{E A S}$ and mesh quality presented by [31].

Table 3. Mesh quality evaluation by equiangle skew.

\begin{tabular}{llll}
\hline QEAs range & Elements & \% & Mesh quality \\
\hline $0-0.25$ & 26711 & 97.54 & Excellent \\
$0.25-0.5$ & 630 & 2.3 & Good \\
$0.5-0.75$ & 44 & 0.16 & Fair \\
\hline
\end{tabular}

The mesh-quality distribution using $Q_{A R}$ is summarised in Table 4. By definition, $Q_{A R}$ is greater than 1 and, when it is equal to 1 , the element is equilateral [31]. In this case, the maximum value of $Q_{A R}$ is 1.75 and the $94.41 \%$ of the elements are in the $Q_{A R}$ range of 1-1.1, which is very close to the equilateral shape.
Table 4. Mesh quality evaluation by aspect ratio.

\begin{tabular}{lll}
\hline $\mathbf{Q}_{\text {AR }}$ range & Elements & \% \\
\hline $1-1.1$ & 25855 & 94.41 \\
$1.1-1.2$ & 1236 & 4.51 \\
$1.2-1.3$ & 227 & 0.83 \\
$1.3-1.4$ & 38 & 0.14 \\
$1.4-1.5$ & 19 & 0.07 \\
$1.5-1.75$ & 10 & 0.04 \\
\hline
\end{tabular}

\subsubsection{Operating Conditions and Physical Properties}

The operating pressure of the system modelled is the atmospheric one which was measured for each steady state selected $(97282-97150 \mathrm{~Pa})$. The thermophysical properties of the fluid have been defined for moist air at atmospheric pressure. The range of its relative humidity measured is 22.5$29.4 \%$ for temperatures between $297 \mathrm{~K}$ and $300 \mathrm{~K}$. The air properties can be described by the following equations, evaluated for the highest air humidity $(29.4 \%)$ and derived from the available studies [32], in which the temperature must be considered in $\mathrm{K}$ :

$$
\begin{gathered}
\rho_{f}=2.8 \cdot \exp (-0.00566 \cdot \mathrm{T})+0.7784 \cdot \exp (-0.000848 \cdot \mathrm{T}), \mathrm{kg} / \mathrm{m}^{3} \\
\mu=\frac{1.45810^{-6} \cdot T^{3 / 2}}{T+110.4}, \mathrm{~kg} / \mathrm{m}-\mathrm{s}
\end{gathered}
$$




$$
\begin{aligned}
& \quad c_{p f}=2.251 \cdot 10^{-10} \cdot \mathrm{T}^{4}-9.236 \cdot 10^{-7} \cdot \mathrm{T}^{3}+0.001288 \cdot \mathrm{T}^{2}-0.5145 \cdot \mathrm{T}+1070, \mathrm{~J} / \mathrm{kg}-\mathrm{K} \\
& k_{f}=1.588 \cdot 10^{-11} \cdot \mathrm{T}^{3}-5.602 \cdot 10^{-08} \cdot \mathrm{T}^{2}+1.0966 \cdot 10^{-04} \cdot \mathrm{T}+0.00222, \mathrm{~W} / \mathrm{m}-\mathrm{K}
\end{aligned}
$$

The thermophysical properties of solid materials were considered at the temperature range of the selected steady states $(873-1273 \mathrm{~K})$. These properties have been supplied by the data sheets of each material (Table 5) and they were implemented in the commercial CFD code by the definition of new materials in the software database.

\begin{tabular}{|c|c|c|c|}
\hline Material & $\rho, \mathrm{kg} / \mathrm{m}^{3}$ & $c_{p}, \mathrm{~J} / \mathrm{kg}-\mathrm{K}$ & $k, \mathbf{W} / \mathbf{m}-\mathbf{K}$ \\
\hline Copper $(\mathrm{Cu})[33]$ & 8978 & 381 & 387.6 \\
\hline \multirow[t]{2}{*}{ Recrystallized Silicon Carbide (re-SiC) [34] } & \multirow[t]{2}{*}{2700} & \multirow[t]{2}{*}{900} & $26(293 \mathrm{~K})$ \\
\hline & & & 35 (473 K) \\
\hline \multirow{6}{*}{ Steel (AISI 310) [35] } & \multirow{6}{*}{7760} & \multirow{6}{*}{500} & $15(293 \mathrm{~K})$ \\
\hline & & & $16(473 \mathrm{~K})$ \\
\hline & & & $18(673 \mathrm{~K})$ \\
\hline & & & $21(873 \mathrm{~K})$ \\
\hline & & & $24(1073 \mathrm{~K})$ \\
\hline & & & $27(1273 \mathrm{~K})$ \\
\hline \multirow[t]{2}{*}{ Steel (AISI 304L) [36] } & \multirow[t]{2}{*}{7900} & \multirow[t]{2}{*}{500} & 15 \\
\hline & & & $2.2(673 \mathrm{~K})$ \\
\hline \multirow{4}{*}{ Dense concrete 1 [37] } & \multirow[t]{4}{*}{2100} & \multirow[t]{4}{*}{1050} & $1.83(1073 \mathrm{~K})$ \\
\hline & & & $1.83(1473 \mathrm{~K})$ \\
\hline & & & $0.64(673 \mathrm{~K})$ \\
\hline & & & $0.73(873 \mathrm{~K})$ \\
\hline \multirow[t]{4}{*}{ Dense concrete $2[38]$} & \multirow[t]{4}{*}{1900} & \multirow[t]{4}{*}{1070} & $0.81(1073 \mathrm{~K})$ \\
\hline & & & $0.82(1273 \mathrm{~K})$ \\
\hline & & & $1.01(1473 \mathrm{~K})$ \\
\hline & & & $0.15(473 \mathrm{~K})$ \\
\hline \multirow{4}{*}{ Light weight concrete [39] } & \multirow{4}{*}{1310} & \multirow{4}{*}{1100} & $0.17(673 \mathrm{~K})$ \\
\hline & & & $0.20(873 \mathrm{~K})$ \\
\hline & & & $0.22(1073 \mathrm{~K})$ \\
\hline & & & $0.09(673 \mathrm{~K})$ \\
\hline \multirow{5}{*}{ Ceramic fibre [40] } & \multirow{5}{*}{240} & \multirow{5}{*}{1130} & $0.14(873 \mathrm{~K})$ \\
\hline & & & $0.20(1073 \mathrm{~K})$ \\
\hline & & & $0.28(1273 \mathrm{~K})$ \\
\hline & & & $0.07(673 \mathrm{~K})$ \\
\hline & & & $0.09(873 \mathrm{~K})$ \\
\hline \multirow[t]{3}{*}{ Alumina [41] } & \multirow[t]{3}{*}{240} & \multirow[t]{3}{*}{1130} & $0.12(1073 \mathrm{~K})$ \\
\hline & & & $0.16(1273 \mathrm{~K})$ \\
\hline & & & $0.22(1473 \mathrm{~K})$ \\
\hline
\end{tabular}

Table 5. Thermophysical properties of solid materials considered.

\subsubsection{Boundary Conditions}

Several continuum zones have been defined in the solution domain: ambient air, insulating material, and sample (Figure 2). Each area is connected with the next one by the definition of different boundary conditions (Figure 4).

The velocity-inlet condition of the ambient air considers the ambient temperature and zero velocity because the fluid flow is not forced.

The outer walls of the insulating material (Figure 4) have been defined assuming that the natural convection is the main heat-transfer process. The heat transfer coefficient was set to $17.5 \mathrm{~W} / \mathrm{m}^{2} \mathrm{~K}$ [42] and the ambient temperature was included in the wall description. The average temperature of the sample obtained from the selected steady states was fixed in its back surface which is embedded in the insulating material and the sample material is defined in each case studied. Furthermore, the remaining inner walls were coupled with the appropriate boundary zones.

\subsubsection{Solution Method}

A 2D CFD model has been developed by commercial CFD software, in which governing equations, operating conditions, material and fluid properties, and boundary conditions were implemented. The governing equations were solved by a segregated steady-state pressure-based solver, used to simulate incompressible and mildly compressible flows [43], and the convergence criterion was fixed at $10^{-6}$ for the energy, and at $10^{-3}$ as a minimum for the continuity and momentum variables.

Furthermore, the pressure discretization scheme selected in the software was standard, and the algorithm chosen for the pressure-velocity coupling was the so-called simple considered for steady-state condition. The convectiondiffusion upwinding scheme selected was the first order upwind which offers good results for most classes of flows with no complex models enabled [43]. 


\section{Results and Discussion}

\subsection{Validation}

The CFD model was validated by the comparison between the temperature measured experimentally for an AISI 310 steel sample and the numerical values obtained at the same thermocouple locations considering the same steel as sample material. This comparison was performed for three experimental quasi-steady states which were selected according to average sample temperatures $\left(T_{a v}\right)$ close to 873 $\mathrm{K}, 1073 \mathrm{~K}$ and $1273 \mathrm{~K}$. For each case, the average temperature was calculated taking into account the maximum and minimum values of the temperature measured in the sample (Table 6). In most cases, the deviation between experimental data and numerical results were lower than $9 \%$, only the deviation was around $11 \%$ for the thermocouples located in the insulating material when $\mathrm{T}_{\mathrm{av}}=1007.5 \pm 71.3 \mathrm{~K}$. By the comparison between the temperature measurements in the insulating material $\left(T_{7}\right.$ and $\left.T_{8}\right)$ for the three steady states, it was concluded that the high deviation is due to an error in the measuring process. Thus, it has been found that numerical results are in appreciable agreement with experimental data according to studies which dealt with CFD analysis for the evaluation of high-temperature solar systems and allow for acceptable deviations of $9 \%$ [44] [45].

Table 6. Deviation obtained from the comparison between experimental and numerical data considering selected quasi-steady states.

\begin{tabular}{|c|c|c|c|c|c|c|c|c|c|}
\hline \multirow{2}{*}{$\begin{array}{l}T_{\text {av }} \\
\text { Thermocouple }\end{array}$} & \multicolumn{3}{|c|}{$838.1 \pm 37.5 \mathrm{~K}$} & \multicolumn{3}{|c|}{$1007.5 \pm 71.3 \mathrm{~K}$} & \multicolumn{3}{|c|}{$1187.7 \pm 93.0 \mathrm{~K}$} \\
\hline & $\mathbf{T}_{\text {test }}, \mathbf{K}$ & $\mathbf{T}_{\text {sim }}, \mathbf{K}$ & Dev,\% & $\mathbf{T}_{\text {test }}, \mathbf{K}$ & $\mathbf{T}_{\text {sim }}, \mathbf{K}$ & Dev,\% & $\mathbf{T}_{\text {test }}, \mathbf{K}$ & $\mathbf{T}_{\text {sim }}, \mathbf{K}$ & Dev, \% \\
\hline $\mathrm{T} 1$ & 876 & 837 & 4.41 & 1079 & 1006 & 6.73 & 1281 & 1186 & 7.38 \\
\hline $\mathrm{T} 2$ & 874 & 837 & 4.28 & 1076 & 1006 & 6.49 & 1273 & 1186 & 6.82 \\
\hline T3 & 802 & 837 & 4.35 & 1009 & 1006 & 0.32 & 1095 & 1186 & 8.35 \\
\hline $\mathrm{T} 4$ & 832 & 837 & 0.58 & 1023 & 1006 & 1.66 & 1164 & 1186 & 1.93 \\
\hline T5 & 802 & 837 & 4.36 & 968 & 1006 & 4.00 & 1128 & 1186 & 5.21 \\
\hline $\mathrm{T} 7$ & 324 & 324 & 0.19 & 301 & 333 & 10.44 & 325 & 350 & 7.80 \\
\hline $\mathrm{T} 8$ & 321 & 324 & 0.87 & 300 & 333 & 10.79 & 323 & 350 & 8.43 \\
\hline
\end{tabular}

As mentioned, the average temperature of the sample was fixed for each steady state as boundary condition of its back surface. Hence, the simulation uncertainty has been evaluated regarding the upper and lower temperature limit. Figure 5 depicts temperature values together with the measurement and simulation uncertainties. The uncertainty related to the experimental data was obtained considering a thermocouple error of $\pm 0.004 \cdot \mathrm{T}$ which corresponds to a range between \pm 1 $\mathrm{K}$ and $\pm 4 \mathrm{~K}$. However, the range of the simulation uncertainty is between $\pm 2 \mathrm{~K}$ and $\pm 93 \mathrm{~K}$. Figure 4 also shows that experimental data are within the uncertainty range of the simulation. Therefore, it can be concluded that the model accuracy is acceptable.

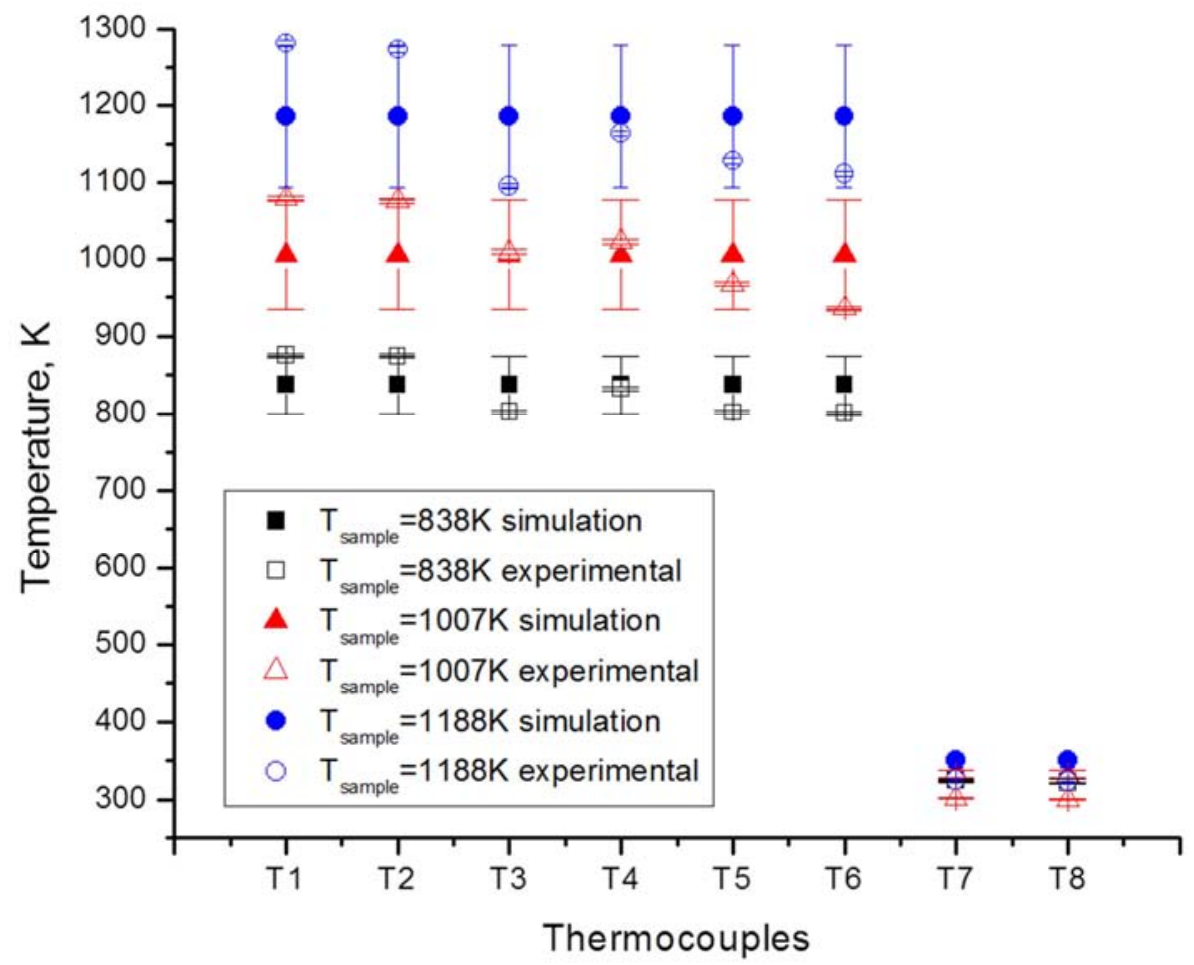

Figure 5. Comparison between experimental measurements and numerical data. 


\subsection{Reliability of High-Temperature Measurement in Solar Systems Using Contact Sensors}

\subsubsection{Evaluation of Temperature Variation in an AISI 310 Steel Sample of $3 \mathrm{~mm}$ Thick}

The tested solar setup, which considers an AISI 310 steel sample of $3 \mathrm{~mm}$ thick, was simulated by the CFD model developed in order to analyse its thermal behaviour. Figure 5 shows the thermal profile obtained when the temperature at the back surface of the sample is fixed at $837 \mathrm{~K}$. It is clearly recognisable the effect of the heat transfer by natural convection on the fluid behaviour. Moreover, the temperature difference between the front surface and the back one is around $2 \mathrm{~K}$ for the selected steady states (see Table 7). Hence, it can be considered in this case that the temperature variation in the AISI 310 steel sample is negligible and the high-temperature control with contact sensors can be a reliable alternative to non-contact ones.

\section{Solar radiation}
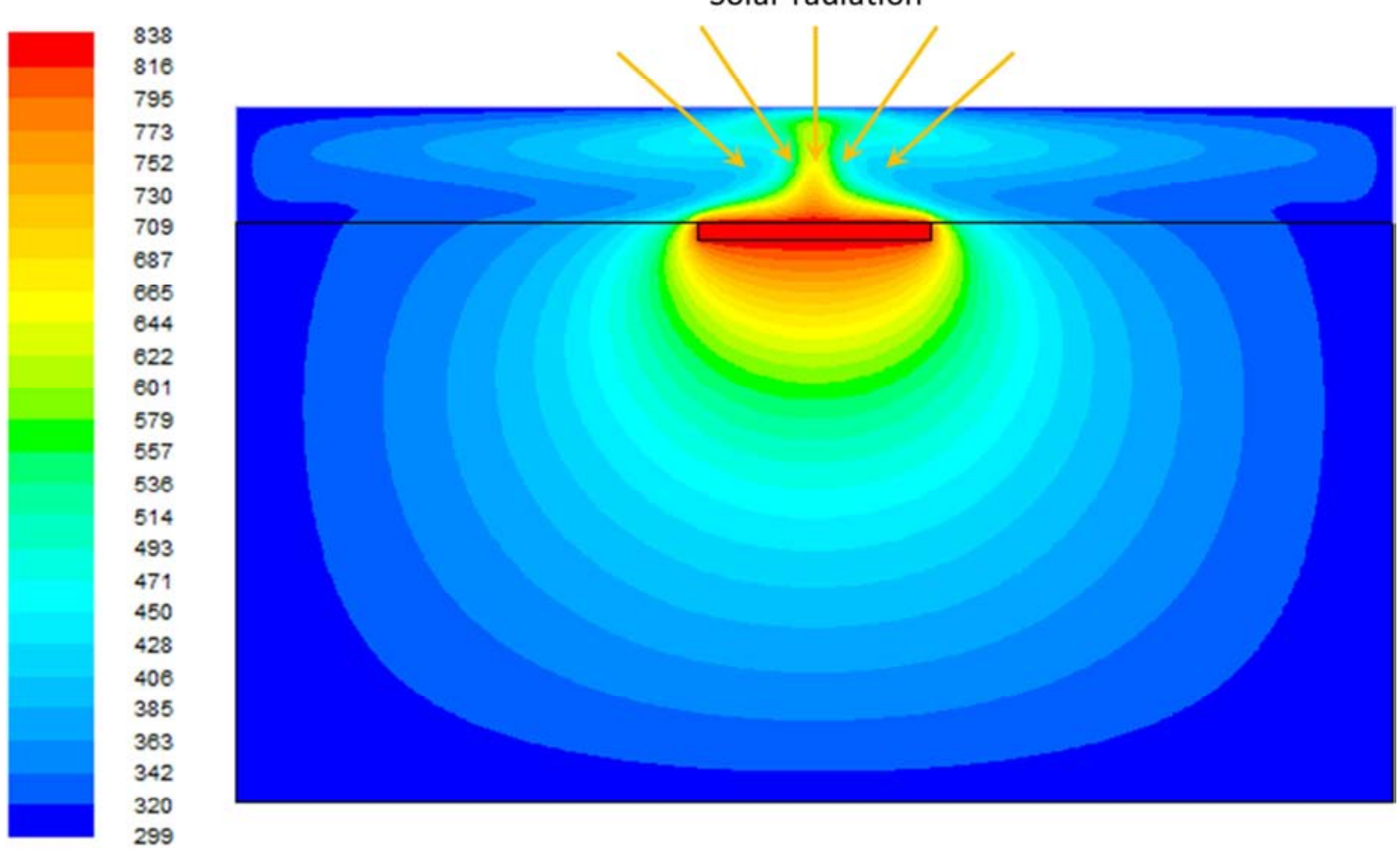

Temperature, $\mathrm{K}$

Figure 6. Thermal profile of the solar setup tested considering $T_{a v}=837 \mathrm{~K}$.

Table 7. Temperature variation in an AISI 310 steel sample of $3 \mathrm{~mm}$ thick.

\begin{tabular}{llll}
\hline Temperature at the back surface, $\mathbf{K}$ & Temperature at the front surface, $\mathbf{K}$ & Temperature variation of the sample, $\mathbf{K}$ & Dev, $\%$ \\
\hline 838.1 & 836.5 & 1.5 & 0.18 \\
1007.5 & 1005.6 & 1.9 & 0.19 \\
1187.7 & 1185.6 & 2.2 & 0.18 \\
\hline
\end{tabular}

\subsubsection{Evaluation of Temperature Variation in Samples of Different Thicknesses Depending on the Thermal Conductivity of the Material}

In order to determine whether contact sensors can be used to monitor high temperatures in samples of different thicknesses and materials (see Table 1), the temperature variation has been evaluated depending on the thermal conductivity.

Figure 6 shows the temperature variation between the front surface and the back one of a 3-mm thick sample made of materials with different thermal conductivities. It has been observed that materials with higher thermal conductivities (Figure 7a) present negligible temperature variation regardless of the temperature reached, whereas insulating materials such as alumina have a high temperature gradient (Figure 7b). Moreover, in all cases, the temperature variation increases with the higher temperature achieved in the sample. Thus, it is obtained that the applicability of the contact sensors to monitor high temperatures is limited to materials with high thermal conductivity.

Furthermore, the temperature variation in the sample has been studied for different thermal conductivities and also considering a thickness range between $1 \mathrm{~mm}$ and $10 \mathrm{~mm}$ (see Figure 8), for the purpose of establishing a mathematical model to predict the thermal behaviour of different samples depending on their thickness and material. 


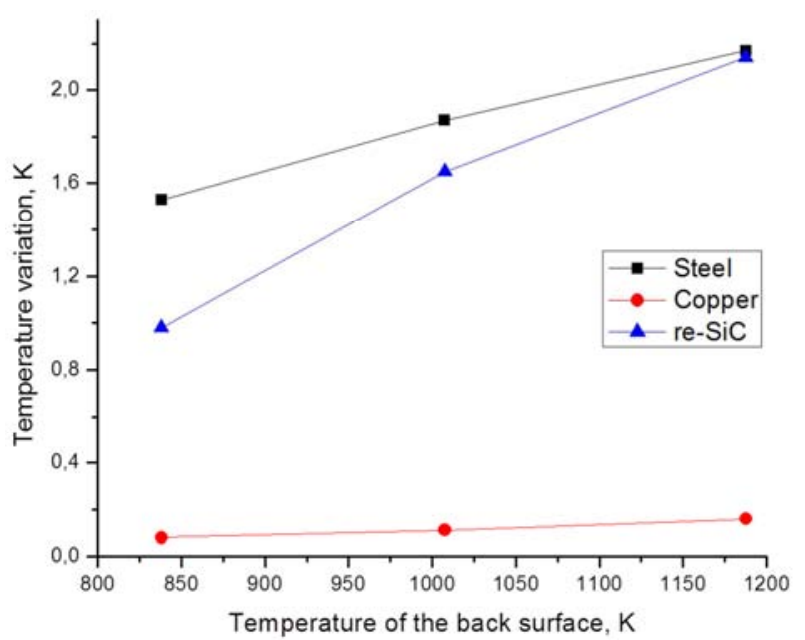

a)

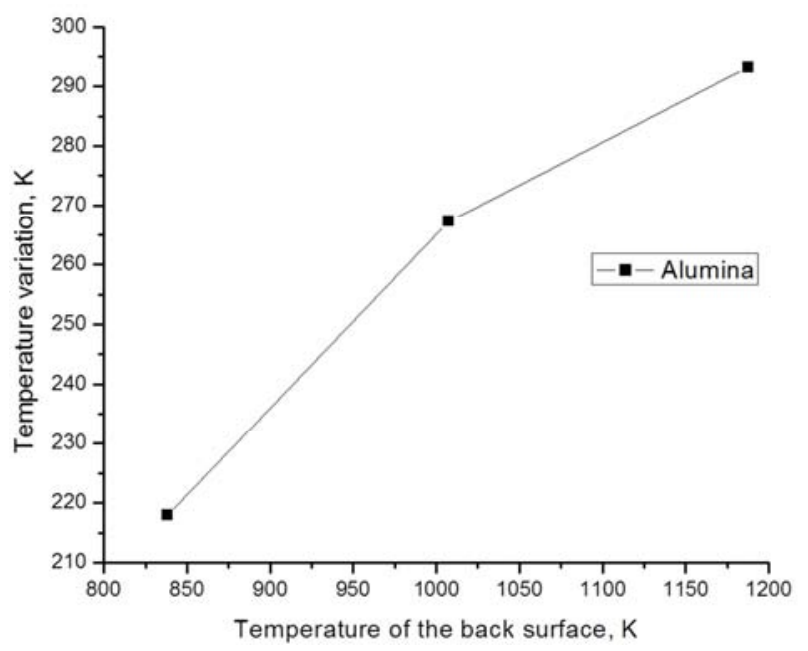

b)

Figure 7. Temperature variation in samples of $3 \mathrm{~mm}$ thick and different materials: a) materials with high thermal conductivity, b) insulating material with low thermal conductivity.

Figure 8 shows the thermal behaviour of each proposed sample regarding a representative value from the three steady states studied which consider temperatures at the back surface of $838 \mathrm{~K}, 1008 \mathrm{~K}$ and $1188 \mathrm{~K}$. The figure depicts the temperature variation in the sample depending on its thermal conductivity for each selected thickness. As a result, it was found the following fitting function:

$$
\ln (\Delta T)=a+b \cdot \ln (k)
$$

where $\Delta T$ is the temperature variation between the front surface and the back one of the sample, $a$ and $b$ are constants coming from the fit, and $k$ is the thermal conductivity of the sample material. The constant values depend on the sample thickness, and they increase at higher thicknesses.

Consequently, the reliability of using contact sensors to measure high temperatures in solar systems can be determined according to Figure 8, considering only those cases which present the condition of $\ln (\Delta T)<2$ to ensure a temperature gradient lower than $10 \mathrm{~K}$.

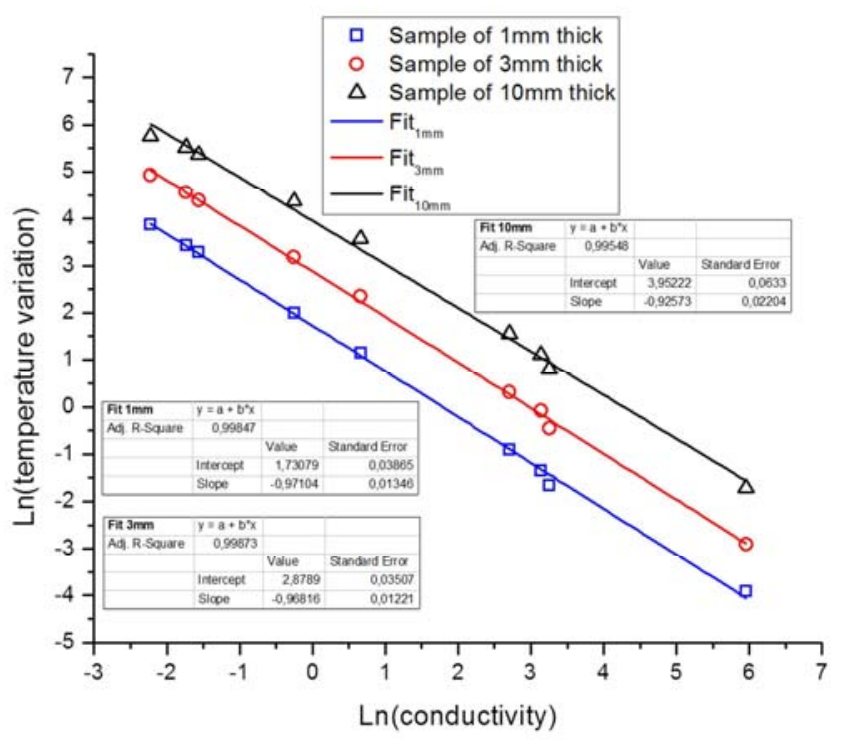

Figure 8. Thermal behaviour of samples with different thicknesses depending on the thermal conductivity of the material.

\section{Conclusions}

The need to estimate surface temperatures in different contexts has led to develop different methodologies over the years. The realization of this measure is difficult, especially in environments where the surface is exposed to concentrated solar radiation. The use of non-contact sensors may seem attractive in these circumstances, however, the sensitivity of these sensors to the reflected solar radiation and the lack of information on the surface emittance make this measurement procedure is not very accurate. In this work a method for surface temperature measurement based on contact sensors has been presented. In the case of materials with high thermal conductivity, contact sensors positioned in the back of the material sample and very close to the surface is the most accurate way to measure surface temperature. Computational Fluid Dynamics simulations have shown the truth of this statement. The higher thermal conductivity of the material, the lower the uncertainty in the measurement of surface temperature using this methodology. This measurement procedure has been applied to AISI $310 \mathrm{~S}$ steel samples in the Plataforma Solar de Almería vertical axis solar furnace SF5 confirming the validity of the simulations.

\section{Acknowledgements}

The authors wish to thank European Commission for its support to the SFERA-II project (Grant Agreement no. 312643, WP12: Pyrometric temperature measurement methods for high-concentration solar facilities and solar simulators; WP13: Determination of physical properties of CSP materials under concentrated solar irradiation) from the Research Infrastructures Activity in the 7th Framework Programme (http://sfera2.sollab.eu). We also thank I. Cañadas, J. Rodríguez and J. Galindo from PSA for their help and contribution during assembly work and operation. 


\section{Nomenclature}

Variable
$c_{p}$
Dev
$E$
$F$
$g$
$h$
$J$
$k$
$p$
$Q_{A R}$
$Q_{E A S}$
$S$
$t$
$T$
$v$
$x$
$y$
$z$

Unit
$\mathrm{J} / \mathrm{kg}-\mathrm{K}$
$\%$
$\mathrm{~J} / \mathrm{kg}$
$\mathrm{N}$
$\mathrm{m} / \mathrm{s}^{2}$
$\mathrm{~J} / \mathrm{kg}$
$\mathrm{kg} / \mathrm{s}-\mathrm{m}^{2}$
$\mathrm{~W} / \mathrm{m}^{2} \mathrm{~K}$
$\mathrm{~N} / \mathrm{m}^{2}$
$\mathrm{dimensionless}$
$\mathrm{dimensionless}$
$\mathrm{s}$
$\mathrm{K}$
$\mathrm{m} / \mathrm{s}$
$\mathrm{m}$
$\mathrm{m}$
$\mathrm{m}$

\section{Greek Symbols}

Variable
$\Delta$
$\mu$
$\rho$
$\tau$

Unit

$\mathrm{kg} / \mathrm{m}-\mathrm{s}$

$\mathrm{kg} / \mathrm{m}^{3}$

$\mathrm{N} / \mathrm{m}^{2}$

\section{Subscripts}

\begin{tabular}{|c|c|}
\hline $\begin{array}{l}\text { Variable } \\
\text { av }\end{array}$ & $\begin{array}{l}\text { Description } \\
\text { average }\end{array}$ \\
\hline eff & effective \\
\hline$f$ & fluid \\
\hline he & heat \\
\hline$j$ & species \\
\hline$m$ & mass \\
\hline $\operatorname{sim}$ & simulation \\
\hline test & experimental \\
\hline
\end{tabular}

\section{References}

[1] L. K. Matthews, R. Sierra, Measurement of temperatures in fibrous insulators subjected to concentrated solar radiation, Solar Energy 38 (1987) 1-7.

[2] B. Schaffner, A. Meier, D. Wuillemin et al., Recycling of hazardous solid waste material using high-temperature solar process heat. II: Reactor design and experimentation. Environmental Science and Technology 37 (1) (2003) 165-170.

[3] S. Kraupl, A. Steinfeld, Operational performance of a 5-kW solar chemical reactor for the co-production of zinc and syngas, Journal of Solar Energy Engineering 125 (1) (2003) 124-126.

[4] D. Hernandez, G. Olalde, G. Bonnier et al., Evaluation of the application of a solar furnace to study the suitability of metal

oxides to be used as secondary reference points in the range 2000-3000 degrees C, Measurement 34 (2) (2003) 101-109.

[5] A. Meier, E. Bonaldi, G. M. Cella et al., Design and experimental investigation of a horizontal rotary reactor for the solar thermal production of lime, Energy 29 (2004) 811-821.

[6] T. Osinga, U. Frommherz, A. Steinfeld et al., Experimental investigation of the solar carbothermic reduction of $\mathrm{ZnO}$ using a two-cavity solar reactor, Journal of Solar Energy Engineering 126 (2004) 633-637.

[7] D. Hirsch, A. Steinfeld, Solar hydrogen production by thermal decomposition of natural gas using a vortex-flow reactor, International Journal of Hydrogen Energy 29 (2004) 47-55.

[8] M. Carasso, M. Becker, Performance Evaluation Standards for Solar Central Receivers, Springer-Verlag, Vol 3, 1990.

[9] R. Siegel and J. Howell, Thermal Radiation Heat Transfer, Third Edition, CRC Press, 1992.

[10] S. Marinetti, P. G. Cesartto, Emissivity estimation for accurate quantitative thermography, NDT\&E International 51 (2012) 127-134.

[11] K. Schurer, A method for measuring infrared emissivities of near-black surfaces at ambient temperatures, Infrared Physics 16 (1976) 157-163.

[12] T. Walach, Emissivity measurements on electronic microcircuits, Measurement 41 (2008) 503-515.

[13] M. Balat-Pichelin, J. F. Robert, J. L. Sans, Emissivity measurements on carbon-carbon composites at high temperature under high vacuum, Applied Surface Science 253 (2006) 778-783.

[14] Ch. Wen, Investigation of steel emissivity behaviors: Exmination of Multiespectral Radiation Thermometry (MRT), International Journal of Heat and Mass Transfer 53 (2010) 2035-2043.

[15] J. Ballestrín, A. Marzo, I. Cañadas and J. Rodríguez, Testing a Solar-Blind Pyrometer, Metrologia 47 (2010) 646-651.

[16] A. Marzo, J. Ballestrín, J. Barbero et al., Solar blind pyrometry not relying on atmospheric absorption bands, Solar Energy 107 (2014) 415-422.

[17] J. Ballestrín, M. López, J. Rodríguez et al., A Solar-Blind IR camera prototype, 15th SolarPACES International Symposium. Berlin, Germany, 2009.

[18] J. Ballestrín, A. Marzo, I. Cañadas, J. Rodríguez, Testing a solar-blind pyrometer. Metrologia 47 (2010) 646-651.

[19] D. Hernandez, G. Olalde, J. M. Gineste et al., Analysis and experimental results of solar-blind temperature measurements in solar furnaces, Journal of Solar Energy Engineering 126 (2004) 645-653.

[20] D. Hernandez, J. Ballestrín, A. Neumann, First Work by the Flux and Temperature Measurement Group (F. T. M) in the SOLLAB Laboratory Alliance, Proceedings of the 13th SolarPACES International Symposium on Solar Thermal Concentrating Technologies, Seville, Spain, Paper No. B6-S6, 2006.

[21] A. Neumann, U. Groer, Experimenting with concentrated sunlight using the DLR solar furnace, Solar Energy 58 (1996) 181-190. 
[22] M. Pfänder, E. Lüpfert et al., Pyrometric temperature measurements on solar thermal high temperature receivers, Journal of Solar Energy Engineering 128 (2006) 285-292.

[23] N. Rohner and A. Neumann, Measurement of high temperatures in the DLR solar furnace by UV-B detection, Journal of Solar Energy Engineering 125 (2003) 152-158.

[24] H. R. Tschudi, G. Morian, Pyrometric temperature measurements in solar furnaces. Journal of Solar Energy Engineering 123 (2001) 164-170.

[25] Agilent Technologies, Practical Temperature Measurements, 1980, Application Note 290.

[26] H. Baker, E. Ryder, N. Baker, Temperature measurement in engineering. Omega Press, Stamford, USA, 1975.

[27] J. Rodríguez, I. Cañada, E. Zarza, "PSA vertical axis solar furnace SF5”, Energy Procedia 49, 1511-1522, (2014).

[28] J. Blazek, Computational fluid dynamics: principles and applications, Elsevier, Oxford, 2008.

[29] G. K. Bachelor, An introduction to fluid dynamics, Cambridge University Press, Cambridge, 1967.

[30] J. K. Versteeg, W. Malalasequera, An introduction to computational fluid dynamics. The finite volume method, Longman Scientific \& Technical, 1995.

[31] ANSYS Inc., ANSYS Fluent Meshing user's guide: Release 16.0, Determining mesh statistics and quality, Canonsburg, PA, 2015, chapter 20.

[32] M. I. Roldán, O. Smirnova, T. Fend, J. L. Casas, E. Zarza, Thermal analysis and design of a volumetric solar absorber depending on the porosity, Renewable Energy 62 (2014) 116128.
[33] Aurubis, Data sheet: Cu-ETP (99.99\% Cu), Revision 1305 EU, 2013.

[34] Sceram Ceramics, Data sheet: Recristalised Silicon Carbide, http://www.sceram.com.

[35] Acerinox, Data sheet: ACX 350 austenitic stainless heatresisting steel, 2012.

[36] ThyssenKrupp Steel, Data sheet of AISI 304/AISI 304L.

[37] Fleischman, Data sheet of dense concretes, 2001.

[38] Thermal Ceramics, Data sheet of dense concretes Firecrete ${ }^{\mathrm{TM}}$, 2001.

[39] Thermal Ceramics, Data sheet of light weight insulating concretes Firelite ${ }^{\mathrm{TM}}, 2002$.

[40] Thermal Ceramics, Data sheet: Pyro-Log ${ }^{\mathrm{TM}}$, Document n. 5-603 S 7/02, 2002.

[41] Thermal Ceramics, Data sheet: Kaowool ${ }^{\mathrm{TM}}$ Board, Document n. 5-7-22 E 1/06, 2006.

[42] J. A. Dantzig, C. L. Tucker III, Modeling in Materials Processing, Cambridge University Press, Cambridge, 2001.

[43] ANSYS Inc., ANSYS Fluent user's guide: Release 16.0, Using the solver, Canonsburg, PA, 2015, chapter 28.

[44] N. Ozalp, D. Jayakrishna, CFD analysis on the influence of helical carving in a vortex flow solar reactor, International Journal of Hydrogen Energy 35 (2010) 6248-6260.

[45] M. I. Roldán, E. Zarza, J. L. Casas, Modelling and testing of a solar-receiver system applied to high-temperature processes, Renewable Energy 76 (2015) 608-618. 